\title{
Removal of pesticide 2,4-D by Conductive-diamond photoelectrochemical oxidation
}

\author{
F. L. Souza ${ }^{1}$, C. Saéz ${ }^{2}$, M. R. V. Lanza ${ }^{1}$, P. Cañizares ${ }^{2}$, M. A. Rodrigo ${ }^{2 *}$ \\ (1) Instituto de Química de São Carlos, Universidade de São Paulo, P.O. Box 780, CEP \\ 13560-970, São Carlos, SP, Brazil \\ (2) Department of Chemical Engineering, Faculty of Chemical Sciences \& Technologies, \\ Universidad de Castilla - La Mancha, Campus Universitario s/n, 13071 Ciudad Real, \\ Spain
}

\begin{abstract}
In this work, the removal of pesticide 2,4-D by single photolysis, electrolysis with BDD anode and a combined UV irradiation - electrolysis is studied. Results demonstrate that although photolysis is completely inefficient in the degradation of this pesticide, light irradiation improves significantly the results obtained by single electrolysis, leading to harsher oxidation conditions, which contribute to reduce the number of intermediates and promote mineralization. Electrolysis with diamond electrodes can attain the complete depletion of the pesticide and its mineralization regardless the current density applied and the light irradiation. In comparing the effect of current density, it was found that process is much efficient operating at $10 \mathrm{~mA} \mathrm{~cm}^{-2}$, attaining complete mineralization with specific current charges below $10 \mathrm{Ah} \mathrm{dm}^{-3}$, in spite of being detected a lower concentration of oxidants. Under absence of chlorides in the supporting electrolyte main intermediates formed were hydroquinone and 4-chlororesorcinol. Under the presence of this anion, 2chlorophenol and 4-chlorophenol were also observed at high concentrations. UV irradiation does not modify the intermediates formed although concentration is lower. An oxidation mechanism is proposed in agreement with other works shown in the literature.
\end{abstract}

\section{Keywords}

Conductive diamond, ultraviolet light irradiation, electrolysis, pesticide, 2,4-D 


\section{Highlights}

- 2,4-D can be efficiently degraded by electrolysis with diamond anodes

- Coupling UV light irradiation to CDEO improve the oxidation of 2,4-D and mineralization

- Single photolysis does not attain any appreciable oxidation of 2,4-D

- Important effect of mediated oxidants on the depletion of 2,4-D by photoelectrolysis

*Corresponding author

Tel: (+34)902204100 ext. 3411

Fax: (+34)926295256

e-mail: manuel.rodrigo@uclm.es 


\section{Introduction}

In the recent years, there is an increasing concern of agencies (such as EPA) and scientific community about the use of pesticides because of their high risks to human health and the environment $[1,2]$. In this context, the 2,4-dichlorophenoxyacetic acid (2,4-D) is a chlorinated phenoxy herbicide, widely used to control many types of broadleaf weeds. This systemic herbicide is considered moderately toxic by World Health Organization and it is known to affect the nervous system of humans and animals. Since this compound exhibit high water-solubility, lifetime and mobility, its continuous use may cause soil percolation and groundwater contamination [3]. Furthermore, the biorefractory character of chlorophenoxy herbicides makes necessary the development of new treatment technologies to eliminate this type of pesticides from contaminated water and soil [4].

Electrochemical oxidation with boron-doped diamond anodes is very efficient in the treatment of wastewater containing recalcitrant compounds [5-9]. This fact is typically associated to the high chemical and electrochemical stability, robustness, weak electrode fouling and long service life [10]. Furthermore, this type of electrolysis is known for generating large quantities of hydroxyl radicals as well as many others oxidants [11]. Other important characteristic is its efficient and synergistic coupling with other technologies such as the irradiation of ultrasounds (US) or UV-light [12].

Many works in the literature study the combination of UV light irradiation and electrolysis for the removal of pollutants such as dyes [13-15], pharmaceutics [16], pesticides [17, 18], phthalates [19], organic polymers [20] and leachate [21]. Results shown in those works indicated improvement in the removal rates explained by heterogeneous and homogenous catalytic processes related to activation of oxidants. These works are not limited only to the use of diamond coatings as anodic material but they are also focused on the use of dimensionally stable anodes (DSA $\left.{ }^{\circledR}\right)$ [22][23-25] and $\mathrm{TiO}_{2}$ electrodes [26, 27]. In this context, in previous works, our group studied the electrooxidation process with UV light irradiation for the oxidation of dimethyl phthalate from synthetic wastewater using both diamond anode and DSA electrodes in a flow reactor. The results demonstrated that irradiation of light makes the oxidation process more efficient in special at higher current densities (when more oxidants can be 
electrochemically produced). In addition, the use of DDB electrode was demonstrated to be the most attractive because of the lower requirements of UV light irradiation [19] and its higher efficiency in the absence of chlorides.

Regarding pesticide 2,4-D, there are several studies in which its removal has been studied by different advanced oxidation process like Fenton [28, 29], Electro-Fenton [28, 30], photoelectron-Fenton[31, 32], electro-oxidation [33-35] and photolysis [36]. Very interesting results were obtained by the group of Brillas in the comparison of technologies which pointed out the effect of the oxidants reagents produced in the electrolyte and the oxidation mechanisms, being the most relevant intermediates detected chloroderivates, such as 2,4 dichlorophenol, 4,6-dichlorophenol, chlorohydroquinone, chlorobenzoquinone and carboxylics acids like glycolic, glyoxylic, maleic, fumaric and oxalic acids. The most important fact demonstrated by photoelectron-Fenton process is that that UV radiation plays a secondary role in indirect reactions.

Combination of UV irradiation and electrolysis is one of the most promising treatment alternatives for the depletion of low concentration of pollutants from wastewater [17, 37-39]. Electrolysis is known to produce significant concentration of oxidant species by the oxidation of salts (sulfate, phosphate, chloride, carbonate, etc.), oxygen (ozone) or by the reduction of oxygen (hydrogen peroxide). These oxidants need to be activated in the solution in order to be effective, most likely as radicals, and this activation may occur either by combination of oxidants (f.i. formation of hydroxyl radicals when ozone and hydrogen peroxide combined) or by irradiation of UV light or US [40-42]. In this later case irradiation does not need to be focus on the anode surface but in the bulk volume of wastewater once oxidants have been produced. For this reason, the purpose of the present study was to evaluate the applicability of the oxidation of 2,4D with a coupled electrolytic- UV irradiation technology. The effect on results of the supporting electrolyte and current density are also going to be studied.

\section{Materials and Methods}

\subsection{Chemicals}


All chemicals, including anhydrous sodium sulphate, sodium chloride (Fluka, Spain), 2,4 dichlorophenoxyacetic acid, hydroquinone, 1,4 - benzoquinone, 4 chlororesorcinol, 2 - chlorophenol, 2,4 - dichlorophenol (Sigma-Aldrich) were analytical grade and used as received. Acetonitrile HPLC grade (Sigma-Aldrich, Spain) was used for the mobile phase. Double deionized water (Millipore Milli-Q system, resistivity = $18.2 \mathrm{M} \Omega \mathrm{cm}$ at $25^{\circ} \mathrm{C}$ ) was used to prepare all solutions.

\subsection{Analysis procedures}

All the samples were filtered with $0.45 \mu \mathrm{m}$ nylon filters from Whatman before their analysis. The decay of herbicide and the evolution of their aromatic products were followed by reversed-phase chromatography, total organic carbon (TOC) and oxygen chemical demand (COD). The chromatography system was an Agilent 1100 series coupled a UV detector. The analytical column Phenomenex Gemini $5 \mu \mathrm{m}$ C18 was used. The mobile phase consisted of 60:40 v/v acetonitrile/ $2 \%$ acetic acid mixture (flow rate of $0.4 \mathrm{~cm}^{3} \mathrm{~min}^{-1}$ ). Other conditions were UV detection wavelength of $280 \mathrm{~nm}$, the temperature oven at $25^{\circ} \mathrm{C}$, and volume injection of $20 \mu \mathrm{L}$. The Total Organic Carbon (TOC) concentration was monitored using a Multi N/C 3100 Analytik Jena analyzer. The Chemical Oxygen Demand (COD) was monitored using a HACH DR200 analyzer.

Chloride anions $\left(\mathrm{Cl}^{-}, \mathrm{ClO}_{3}{ }^{-}, \mathrm{ClO}_{4}{ }^{-}\right)$were determined by ion chromatography using a Shimadzu LC-20A equipped with a Shodex IC I-524A column; mobile phase, $2.5 \mathrm{mM}$ phthalic acid at $\mathrm{pH}$ 4.0; flow rate, $1 \times 10^{-3} \mathrm{dm}^{3} \mathrm{~min}^{-1}$. Hypochlorite ( $\mathrm{HClO}^{-}$) was determined by titration with $0.001 \mathrm{M} \mathrm{As}_{2} \mathrm{O}_{3}$ in $2.0 \mathrm{M} \mathrm{NaOH}$. Pretreatment of the samples was carried by addition of $2 \times 10^{-3} \mathrm{dm}^{3}$ of $2.0 \mathrm{M} \mathrm{NaOH}$ in order to increase the $\mathrm{pH}$. Peroxosulphate was determinate iodometrically according to Kolthoff \& Carr (1953) [43]. Measurements of $\mathrm{pH}$ were carried out with an InoLab WTW pH-meter.

The specific electrical energy consumption for the electrolytic and photolytic treatments were calculated according to eqs 1 and 2 where $E$ is the cell potential $(\mathrm{V}), \mathrm{t}$ is the electrolysis or photolysis time $t(\mathrm{~h}), I(\mathrm{~A})$ is the applied electric current and $\mathrm{w}$ is the power of the UV lamp (15 watts for the lamp used in this study). 


$$
\begin{aligned}
& W_{\text {electrolysis }}\left(W h g^{-1}\right)=\frac{I(A) \cdot t(h) \cdot E(V)}{m\left(g^{-1}\right)} \\
& W_{\text {photolysis }}\left(W h g^{-1}\right)=\frac{W(W) \cdot t(h)}{m\left(g^{-1}\right)}
\end{aligned}
$$

\subsection{Electrochemical cell}

Electrolyses were carried out in a single compartment electrochemical flow cell. One of the covers of this cell was made of quartz in order to let UV light to access into the reaction media. The other cover was made of a high chemical resistance polymer. The anode was pasted to the polymer cover and a grid cathode to the quartz cover in order to let light irradiates the cathode and anode surface. The inter-electrode gap was about 9 mm. A UV lamp VL-215MC (Vilber Lourmat), $\lambda=254 \mathrm{~nm}$, intensity of $930 \mu \mathrm{W} \mathrm{cm}{ }^{-2}$ and energy 4.43-6.20 eV irradiated 15 watts directly to the quartz cover. More information about this setup can be found elsewhere [19]. Boron-doped diamond electrode provided by Adamant Technologies (Neuchatel, Switzerland) was used as anode and a grid of stainless steel as cathode. Both electrodes were circular (100 mm diameter) covering a geometric area of $78 \mathrm{~cm}^{2}$. The thickness of the BDD coating was 2$3 \mu \mathrm{m}$ of the thickness, the boron concentration was $500 \mathrm{ppm}$, and the $\mathrm{sp}^{3} / \mathrm{sp}^{2}$ ratio was 176. Prior to use in galvanostatic electrolysis assays, the electrode was polarized during $10 \mathrm{~min}$ in a $1 \mathrm{M} \mathrm{Na}_{2} \mathrm{SO}_{4}$ solution at $15 \mathrm{~mA} \mathrm{~cm}^{-2}$ to remove any impurities from its surface. The electro-oxidation was carried out galvanostatically using $1.2 \mathrm{dm}^{3}$ of a solution containing $100.0 \mathrm{mg} \mathrm{dm}^{-3} 2.4 \mathrm{D}$. Experiments were carried out in recirculated batch mode by means of a peristaltic pump with a constant flow rate of $26.4 \mathrm{dm}^{3} \mathrm{~h}^{-1}$. The mass transfer coefficient $\left(\mathrm{K}_{\mathrm{m}}\right)$ of the electrochemical cell within the fluid dynamic conditions used was $8 \cdot 10^{-6} \mathrm{~m} \mathrm{~s}^{-1}$ (calculated using a standard $\mathrm{Fe}(\mathrm{CN}) 6^{3+} / \mathrm{Fe}(\mathrm{CN})_{6}{ }^{2+}$ current limit test). A heat exchanger coupled with a controlled thermostatic bath was used to maintain the temperature at $25^{\circ} \mathrm{C}$. The investigated variables in the electrochemical degradation of the herbicide were: $\mathrm{i})$ the nature of the supporting electrolyte $\left(\mathrm{NaCl}\right.$ and $\left.\mathrm{Na}_{2} \mathrm{SO}_{4}\right)$ by keeping the ionic strength at $0.05 \mathrm{~mol} \mathrm{dm}{ }^{-3}$, ii) the applied current density $\left(10-100 \mathrm{~mA} \mathrm{~cm}^{-2}\right)$. 


\section{Results and discussion}

Figure 1 shows changes in the 2,4-D and TOC concentration during the single photolytic treatment of synthetic wastewater polluted with $100 \mathrm{mg} \mathrm{dm}^{-3}$ of the pesticide and containing sodium sulfate or chloride as salts.

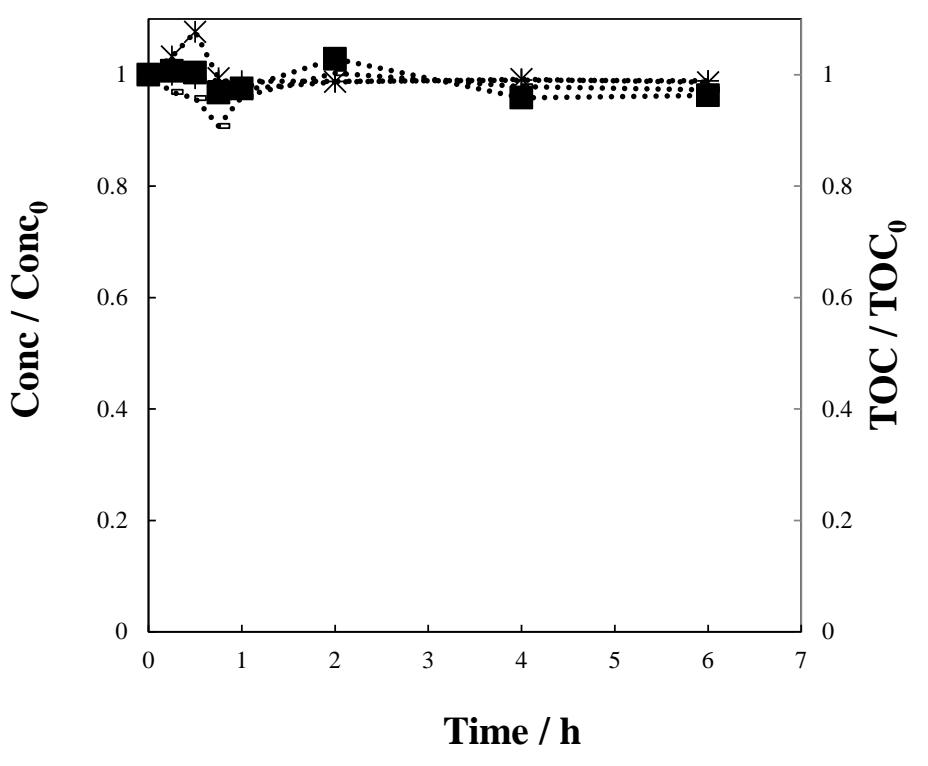

Figure 1. Time course of 2,4 - D and TOC during the photolysis of a solution containing $100 \mathrm{mg} \mathrm{dm}^{-3}$ of 2,4 - D

No significant changes are observed during the 6 hours-long tests but simply random variation associated to the accuracy of the analytical technique. These results clearly indicate that single photolysis is not a good technology for the oxidation of this pesticide. As it can be seen not only the mineralization (TOC) but also the concentration of the raw molecule remained in the initial value suggesting that $2,4-\mathrm{D}$ is completely refractory to this type of treatment.

Figure 2 compares the pesticide removal and COD decay during electrochemical and photo-electrochemical tests. 

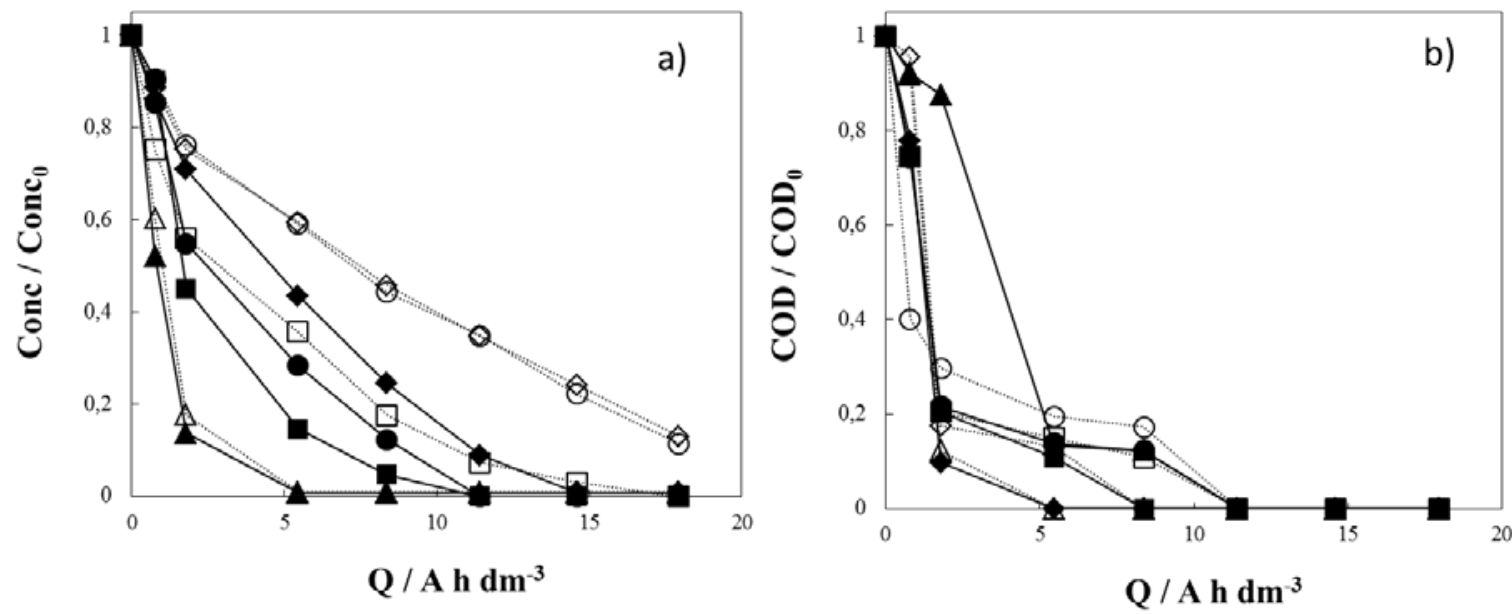

Figure 2. Influence of the current density on the (a) removal of pollutant and (b) relative COD decay as function of the applied charge (Q) during the photo electrochemical process (full points-continuous line) and electrochemical oxidation (empty points-dashed lines) containing $\mathrm{NaCl}$ and $\mathrm{Na}_{2} \mathrm{SO}_{4}$ as supporting electrolyte. $(\boldsymbol{\Delta}, \Delta) \mathrm{Na}_{2} \mathrm{SO}_{4} 10 \mathrm{~mA} \mathrm{~cm}^{-}$

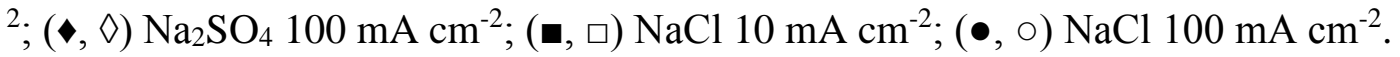

As it can be observed, in this case a very effective oxidation is attained. Both the current density and the supporting electrolyte have a great influence on the process performance although complete removal of the pollutants can be attained in all conditions studied. The lower efficiencies observed at large current densities can be explained by the diffusion control of the pollutant removal rate and a relative greater amount of $\bullet \mathrm{OH}$ radicals wasted in parasite non-oxidizing reactions such as oxygen evolution reaction [5]. Differences between tests with chloride and sulfate media can be explained by the different oxidants that can be formed. UV light irradiation has a positive effect on the removal being this effect more important for the electrolysis carried out at large current densities, where more oxidants are expected to be produced and hence are available for oxidation. In sulfate medium, at $10 \mathrm{~mA} \mathrm{~cm}^{-2}, 2,4-\mathrm{D}$ depletion is achieved in about $5 \mathrm{Ah} \mathrm{dm}^{-3}$ (4 h) for irradiated process while at $100 \mathrm{~mA} \mathrm{~cm}^{-2}$ although it is faster (30 minutes), it requires three times more electrical applied charge. For a better comparison, Table 1 shows the apparent rate constant of the 2,4-D oxidation. As expected, the current density and the use of light irradiation improve the 2,4-D oxidation rate.

Table 1. Apparent rate constant of the electrochemical oxidation and photo electrochemical oxidation of $100 \mathrm{mg} \mathrm{dm}^{-3}$ of 2,4-D. 


\begin{tabular}{|c|c|c|c|}
\hline Process & $\mathrm{j}\left(\mathrm{mA} \mathrm{cm}^{-2}\right)$ & Electrolyte & $\left.\mathrm{k}^{-1}\right)$ \\
\hline \multirow{3}{*}{$\begin{array}{c}\text { Electrochemical } \\
\text { oxidation }\end{array}$} & 10 & $\mathrm{NaCl}$ & 0.08 \\
\cline { 2 - 4 } & 10 & $\mathrm{Na}_{2} \mathrm{SO}_{4}$ & 0.12 \\
\cline { 2 - 4 } & 100 & $\mathrm{NaCl}$ & 0.45 \\
\hline \multirow{2}{*}{$\begin{array}{c}\text { Photo } \\
\text { electrochemical } \\
\text { oxidation }\end{array}$} & 100 & $\mathrm{Na}_{2} \mathrm{SO}_{4}$ & 0.44 \\
\cline { 2 - 4 } & 10 & $\mathrm{NaCl}$ & 0.11 \\
\cline { 2 - 4 } & 10 & $\mathrm{Na}_{2} \mathrm{SO}_{4}$ & 0.12 \\
\hline
\end{tabular}
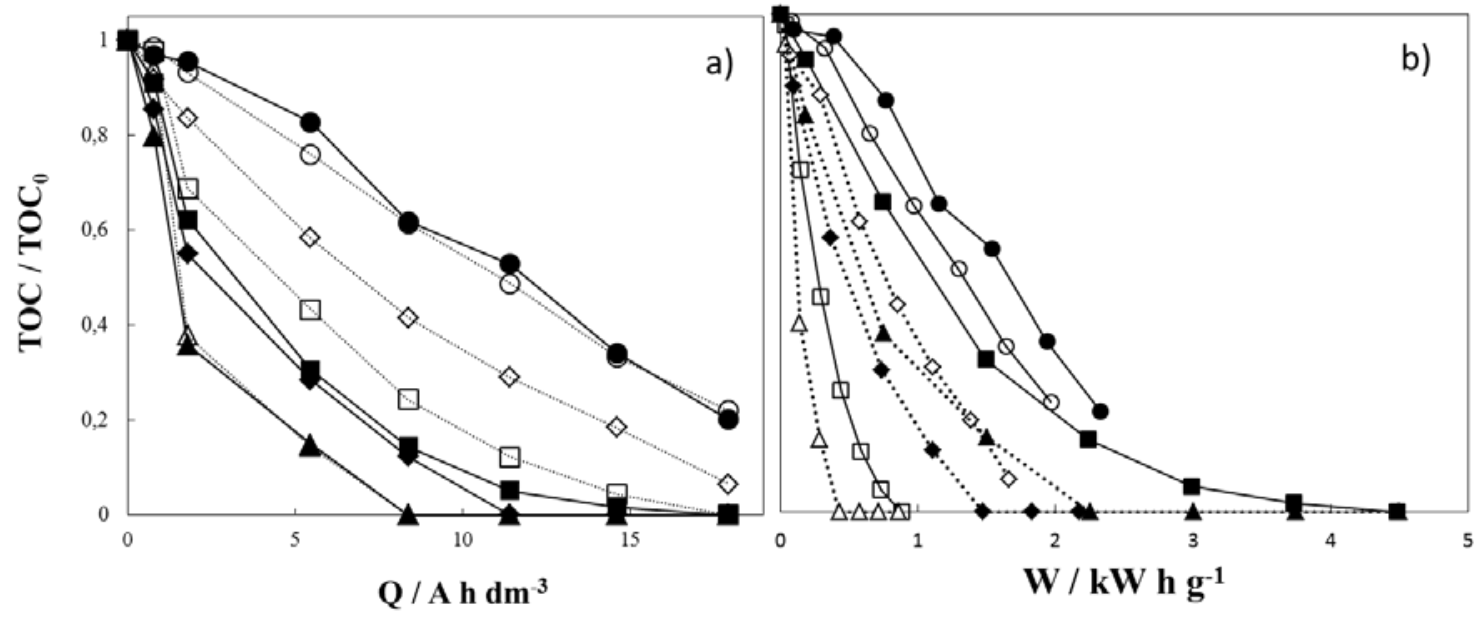

Figure 3. (a) Relative TOC decay as a function of the applied charge per unit volume of electrolyzed solution $(Q)$ and (b) Relative TOC decay as a function of the energy consumption during the photo electrochemical process (full points- continuous line) and electrochemical oxidation (empty points- dashed line) containing $\mathrm{NaCl}$ and $\mathrm{Na}_{2} \mathrm{SO}_{4}$ as supporting electrolyte. $(\boldsymbol{\Delta}, \Delta) \mathrm{Na}_{2} \mathrm{SO}_{4} 10 \mathrm{~mA} \mathrm{~cm}^{-2} ;(\diamond, \diamond) \mathrm{Na}_{2} \mathrm{SO}_{4} 100 \mathrm{~mA} \mathrm{~cm}^{-2}$; (๘, $\left.\square\right)$ $\mathrm{NaCl} 10 \mathrm{~mA} \mathrm{~cm}{ }^{-2} ;(\bullet, \circ) \mathrm{NaCl} 100 \mathrm{~mA} \mathrm{~cm}^{-2}$.

Comparison in terms of mineralization is a little bit different as it can be seen in Figure 3a. The most efficient removal is attained in sulfate media at low current density and under these conditions light irradiation does not play a significant role on results because TOC vs Q data clearly lay over the same line. In increasing the current density, in the treatment of the synthetic wastewater containing sulfate it can be observed a great 
influence of light irradiation, much greater than that observed in both treatment tests made for wastewater with chlorides. This increase indicates that large concentration of oxidants are produced and activated under these conditions. Peroxosulfate is known to be produced during the CDEO of sulfate solutions (either by direct processes or by processes mediated by hydroxyl radicals as shown in eqs. 3 to 6) and activation with light to produce sulfate radicals (eq. 7) is also confirmed in previous studies [42]. In terms of the electrical energy consumption (Fig. 3b) it can be seen that the additional energy cost of light irradiation is compensated by the lower charge required in the electrochemical process operating at high current densities but not at low current densities.

$$
\begin{gathered}
\mathrm{HSO}_{4}^{-} \rightarrow\left(\mathrm{HSO}_{4}^{-}\right)^{\cdot}+\mathrm{e}^{-} \\
\mathrm{HSO}_{4}^{-}+\mathrm{OH}^{\cdot} \rightarrow \mathrm{SO}_{4}^{-\cdot}+\mathrm{H}_{2} \mathrm{O} \\
\mathrm{SO}_{4}^{--}+\mathrm{OH}^{-} \rightarrow \mathrm{HSO}_{5}^{-} \\
\mathrm{SO}_{4}^{-{ }^{-}}+\mathrm{SO}_{4}^{-} \rightarrow \mathrm{S}_{2} \mathrm{O}_{8}{ }^{2-} \\
\mathrm{S}_{2} \mathrm{O}_{8}{ }^{2-}+h v \rightarrow 2\left(\mathrm{SO}_{4}^{-}\right)^{-}
\end{gathered}
$$

Regarding the electrolysis of chloride solutions a much more complex chemistry is expected to be produced with the formation not only of gaseous chlorine and hypochlorite but also of undesirable chlorates and perchlorates (eqs. 8 to 12). In this case, light irradiation favours the decomposition of hypochlorite (eqs. 13 and 14). Fig. 3b shows that in this case the extra cost of light irradiation does not compensate the lower electric charge required in the photoelectrochemical process operated at low current densities.

$$
\begin{aligned}
& \mathrm{Cl}^{-}+\mathrm{H}_{2} \mathrm{O} \rightarrow \mathrm{HClO}+\mathrm{H}^{+}+2 \mathrm{e}^{-} \\
& \mathrm{Cl}^{-}+\mathrm{OH} \cdot \rightarrow \mathrm{ClO}^{-}+\mathrm{H}^{+}+\mathrm{e}^{-} \\
& \mathrm{ClO}^{-}+\mathrm{OH} \cdot \rightarrow \mathrm{ClO}_{2}^{-}+\mathrm{H}^{+}+\mathrm{e}^{-} \\
& \mathrm{ClO}_{2}^{-}+\mathrm{OH} \cdot \rightarrow \mathrm{ClO}_{3}^{-}+\mathrm{H}^{+}+\mathrm{e}^{-} \\
& \mathrm{ClO}_{3}^{-}+\mathrm{OH} \cdot \rightarrow \mathrm{ClO}_{4}^{-}+\mathrm{H}^{+}+\mathrm{e}^{-} \\
& \mathrm{ClO}^{-}+\mathrm{h} v \rightarrow \mathrm{O}^{-} \cdot+\mathrm{Cl}^{-} \\
& \mathrm{O}^{-} \cdot+\mathrm{H}{ }_{2} \mathrm{O} \rightarrow \mathrm{OH}^{-}+\mathrm{OH} \cdot
\end{aligned}
$$


In order to clarify the effect of the oxidants produced, Figure 4 compares the concentration of peroxodisulfate monitored during the different tests carried out.

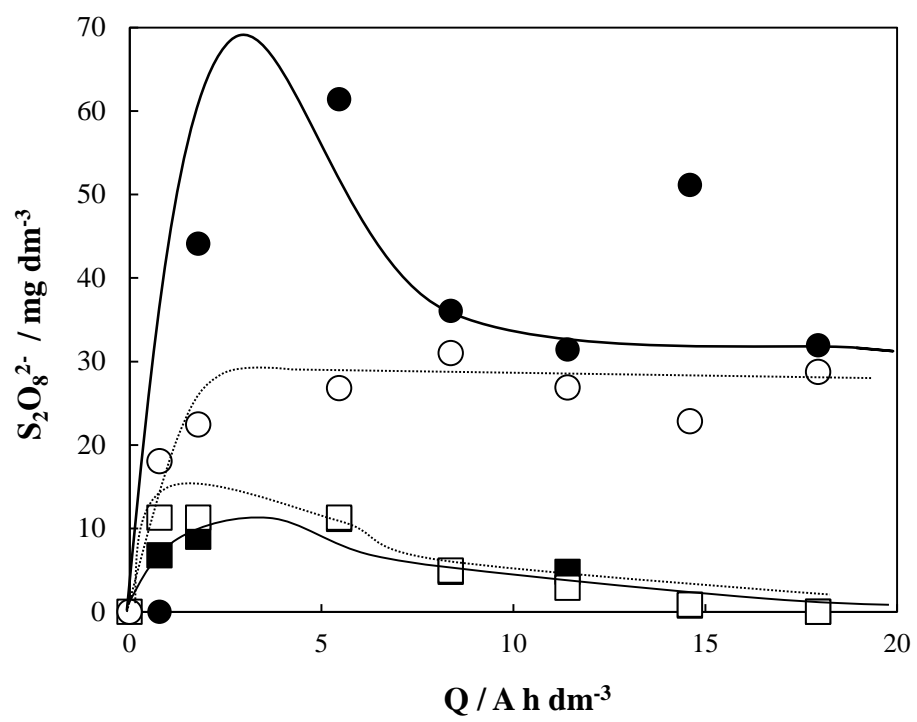

Figure 4. Evolution of peroxodisulfate compound with the applied charge applied (Q) during the photo electrolyses (full points) and electrolyses (empty points) of $100 \mathrm{mg} \mathrm{dm}^{-}$ ${ }^{3} 2,4 \mathrm{D}$ in sulfate media (ש) $10 \mathrm{~mA} \mathrm{~cm}^{-2}$ and (•) $100 \mathrm{~mA} \mathrm{~cm}^{-2}$.

As it can be observed, the higher the current density, the higher is the resulting concentration of peroxosulfate in the electrolyzed solution. Opposite of what it could be expected according to the degradation of the pesticide the trends are not very different and concentrations are comparable. Obviously, peroxodisulfate decomposed by light is not measured by the analytical technique used. This means that only low concentration of sulfate radicals are produced but they are enough to explain the much better removal of these species not only in the oxidation of the raw molecule but also in the oxidation of all the intermediates formed in the system. It is important to bear in mind that single photolysis do not attain any oxidation of 2,4-D and that no other explanation can be given to the enhancement observed during the UV irradiated electrolysis. An important point is that no chlorinated oxidants were detected in these tests in spite of the presence of chlorine in the pesticide molecule. Low concentration of pesticide used can help to explain this absence. Regarding oxidant produced in wastewater containing chloride, Figure 5 focuses on the comparison of chlorine speciation at the two current densities applied. 

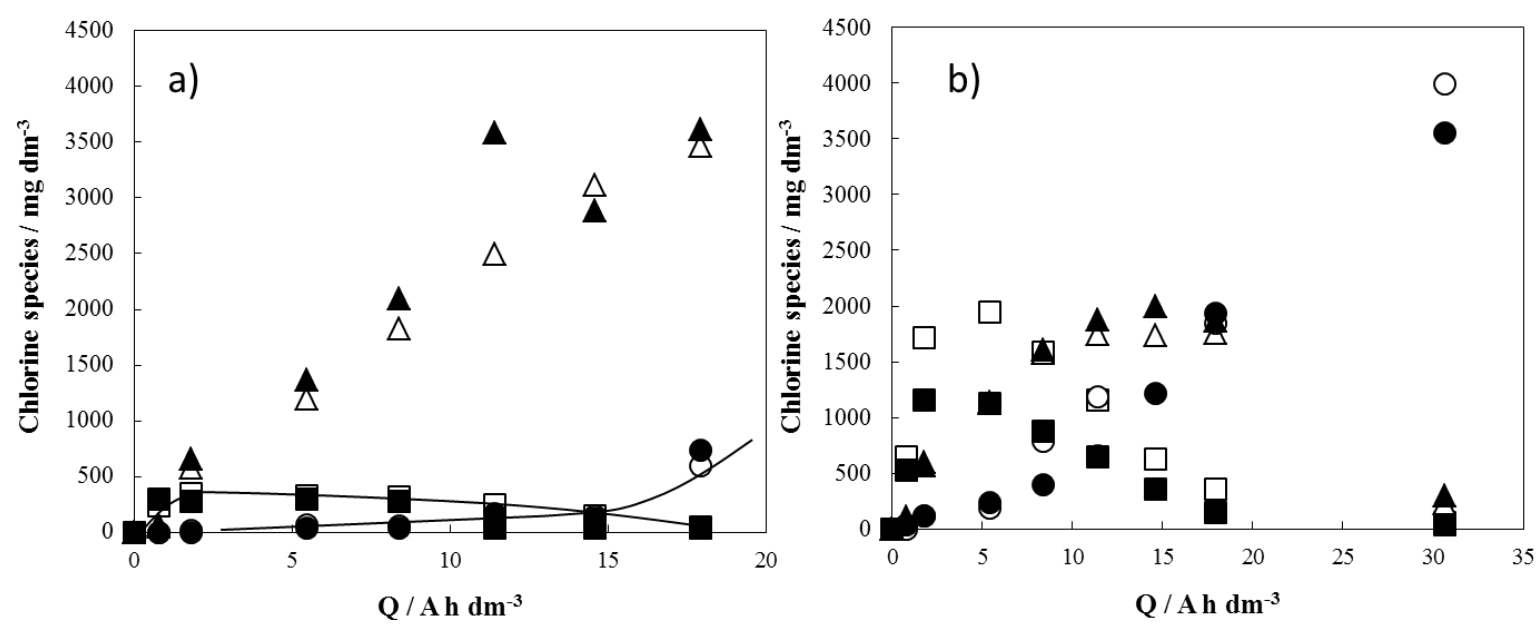

Figure 5. Evolution of chlorine compounds with the applied charge applied (Q) during the photo electrolysis (full points) and electrolyses (empty points) of $100 \mathrm{mg} \mathrm{dm}^{-3} 2.4 \mathrm{D}$ in chloride media (a) $10 \mathrm{~mA} \mathrm{~cm}{ }^{-2}$ and (b) $100 \mathrm{~mA} \mathrm{~cm}^{-2}$. $(\mathbf{\square}, \square)$ hypochlorite; $(\boldsymbol{\Delta}, \Delta)$ Chlorate $(\bullet, \circ)$ perchlorate.

As for the sulfate, no significant differences are attained in the electrolyte when UV light is irradiated, in spite of the great effect observed in the degradation of the molecule: concentration of species seem to lay over the same lines. In comparing the effect of the current density it can be observed a higher production of perchlorate working at higher current densities while chlorates is the most important species formed in the low current density experiment. Both species are hazardous and they should be prevented in a real treatment. The treatment for these species is complex and it would make necessary the application of complementary treatment such as ion exchange or reverse osmosis. Anyhow, in this study they are giving valuable information about the mechanisms of oxidation. Regarding hypochlorite, the most active species in the oxidation, concentration is much smaller in UV irradiated experiments. This may help to explain the results obtained, because this lower concentration can be related to the formation of chlorine radicals in the reaction media that improve the oxidation results and prevents formation of chlorates and perchlorates.

Regarding the oxidation mechanisms, Figure 6 compares the changes of aromatics intermediates in chlorine medium as a function of the charge applied. 

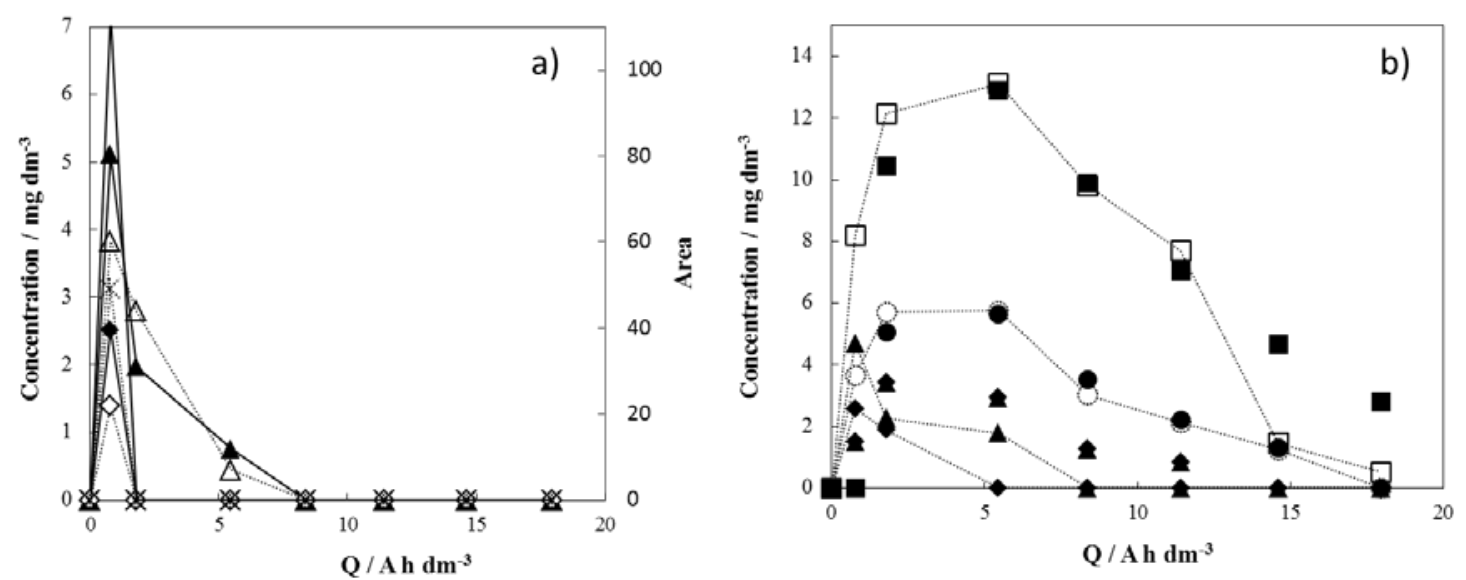

Figure 6. Concentrations of aromatics intermediates found during the electrolyses (full points) and photo-electrolyses (empty points) of 2,4- D in chloride media (a) $10 \mathrm{~mA} \mathrm{~cm}^{-}$ 2 and (b) $100 \mathrm{~mA} \mathrm{~cm}^{-2}$ as a function of the applied charge applied (Q) during the electrochemical oxidation (full points) and photo electrochemical process (empty points). $(\boldsymbol{\Delta}, \Delta)$ 2-Chlorophenol; $(\diamond, \diamond)$ 4-Clorofenol; $(\mathbf{\square}, \square) 2.6$ hydroquinone; $(\bullet, \circ) 4$ Chlororesorcinol; $(+, *)$ No identified

As it can be seen, same intermediates were found in the both processes (single electrolysis and UV irradiated photo-electrolysis), indicating that the primary mechanism of 2,4-D degradation is the same. The main aromatic intermediates were hydroquinone, 4chlororesorcinol, 2-chlorophenol and 4-chlorophenol. The concentrations of these species increase gradually with the applied charge achieving maximum concentration for about 1 Ah $\mathrm{dm}^{-3}$ at $10 \mathrm{~mA} \mathrm{~cm}{ }^{-2}$ and about $5 \mathrm{Ah} \mathrm{dm}^{-3}$ at $100 \mathrm{~mA} \mathrm{~cm}^{-2}$. Then, they decay till be completely oxidized, behaving as reaction intermediates regardless of the current density or light irradiation. In comparing the effect of current density, it can be seen that the process is much more efficient at low current densities because the concentration of intermediates is much smaller. In addition, light irradiation make oxidation conditions harsher and lower concentration of intermediates can be observed. These results are in agreement with the results observed for mineralization, which faster mineralization was obtained at lower current densities and in the photo electrochemical process.

Figure 7 focuses on the aromatics compounds found during the oxidation test with sulfate medium. As can be seen, only low concentration of hydroquinone was found in the electrolyses at $10 \mathrm{~mA} \mathrm{~cm}{ }^{-2}$, being this concentration slightly lower in under UV irradiation. At higher current density 4-chlororesorcinol and benzoquinone were also 
found in addition to hydroquinone. However, much lower concentration were found as compared to chloride medium.
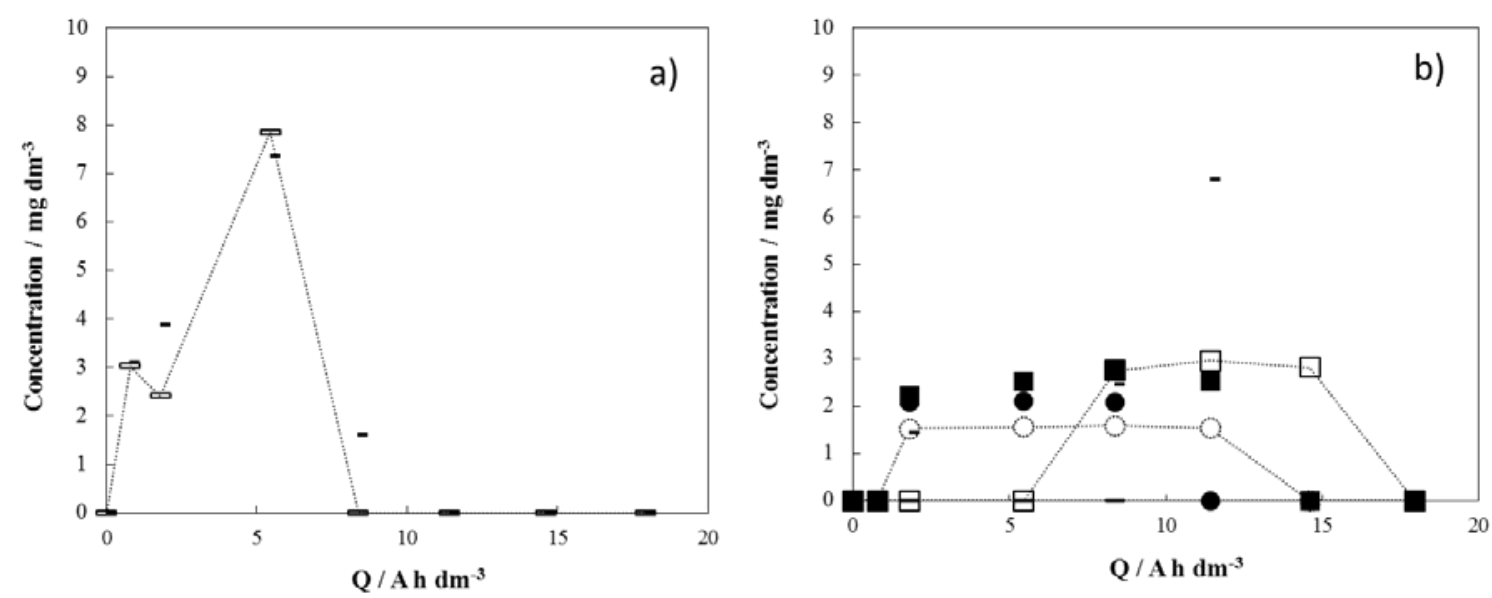

Figure 7. Concentrations of aromatics intermediates found during the electrolyses (full points) and photo-electrolyses (empty points) of 2,4 D in sulfate media (a) $10 \mathrm{~mA} \mathrm{~cm} \mathrm{c}^{-2}$ and (b) $100 \mathrm{~mA} \mathrm{~cm} \mathrm{~cm}^{-2}$ as a function of the applied charge applied (Q) during the electrochemical oxidation (full points) and photo electrochemical process (empty points). $(-,-)$ Benzoquinone; $(\mathbf{\square}, \square)$ hydroquinone; $(\bullet, \circ)$ 4-chlororesorcinol

By analyzing the products in Figs 6 and 7, it may be suggested that the main degradation pathway is the elimination of alkyl group bound followed by the addition of $\mathrm{OH}$ species allowing the formation of the 4-chlororesorcinol according to the mechanisms shown in Figure 8. 

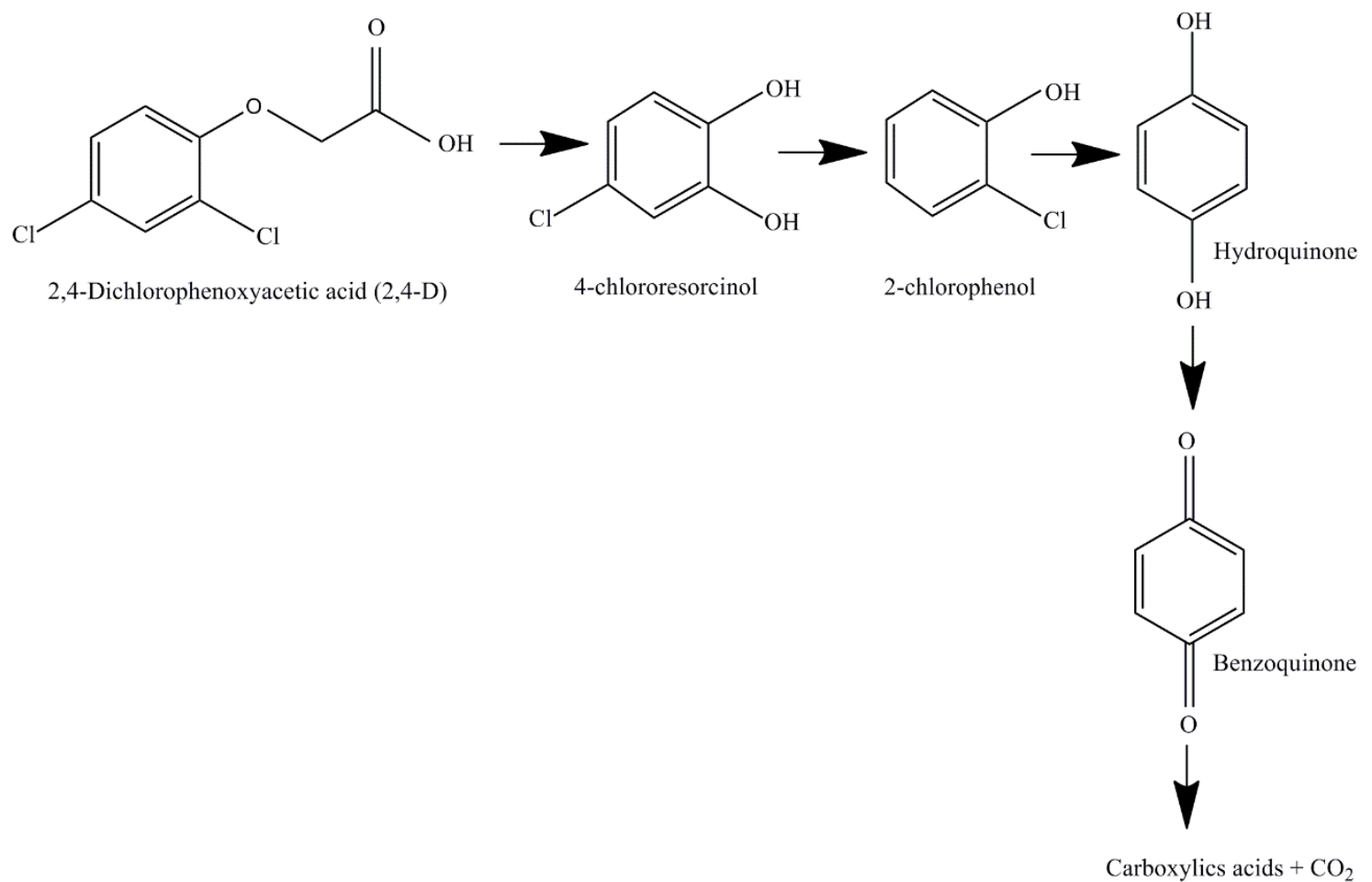

Figure 8. Mechanism for the removal of 2,4-D according to the intermediates detected in this work.

However, in chloride medium the substitution of the chlorine leads to formation of the chloro phenolic compounds. This behavior is probable due to high production of the active chlorine atoms from the anode oxidation of $\mathrm{Cl}^{-}$ions which might participate in the degradation of 2,4 - D. In sulfate medium, where only $\bullet \mathrm{OH}$ is considered as the main oxidant, the principal pathway after the 4-chlororesorcinol formation is the consecutive hydroxylation of aromatic ring leading to formation of hydroquinone, which afterwards is oxidized to benzoquinone. Brillas et al. studied the oxidation of 2.4-D by electro-Fenton using a boron-doped diamond (BDD) anode [31]. In agreement with these authors the main aromatic intermediate found was 2,4-dichlorophenol and oxalic acid as carboxylic acid. The 2,4-D degradation pathway also has been reported by Fontmorin [33, 44] with electrolysis using bare graphite felt as anode. The results showed that chlorohydroquinone and 4-chlorocatechol were the most important intermediates found and 2,4dichlorophenol and glycolic acid were also detected. Taking in account these possibilities, after the rupture between the alkyl group and benzene ring, the formation of 2,4dichlorophenol is possible. Further oxidation of this compound leads to formation of 4- 
chlororesorcinol, chlorophenol, hydroquinone and benzoquinone. Successive attacks of hydroxyl radical leads to carboxylic acids which are finally converted to $\mathrm{CO}_{2}$.

\section{Conclusions}

From this work, the following conclusions can be drawn:

- Wastewater containing 2,4-D can be mineralized by single electrolysis with diamond anodes and by combined UV irradiation photoelectrolysis. Single photolysis is completely inefficient for the oxidation of 2,4-D.

- Main aromatic intermediates formed in the oxidation of 2,4-D depends on the presence of chloride in the supporting electrolyte. In the absence of chloride, hydroquinone and 4-chlororesorcinol are the main intermediates formed while the presence of chloride lead also to the formation of important concentrations of 2chlorophenol and 4-chlorophenol

- In the electrolysis of wastewater containing sulfate anions, UV irradiation influences more importantly at high current densities, when the electrochemical production of persulfate is promoted. In the electrolysis of solutions containing chloride anions the effect on the oxidation of the raw molecule of UV irradiation is very important but the effect on the mineralization is low at high current densities. This observation can be related to the formation of chlorine radicals in the reaction media that improve the oxidation results and prevents formation of chlorates and perchlorates.

\section{Acknowledgements}

The authors acknowledge funding support from the EU and Spanish Government through the MINECO Project CTM2013-45612-R, FEDER 2007-2013 PP201010 (Planta Piloto de Estación de Estación de Regeneración de Aguas Depuradas) and INNOCAMPUS. Brazil government by grant 2014/02580-7, Foundation for Research Support of the State of São Paulo (FAPESP) is gratefully acknowledged.

\section{References}


[1] M.A. Oturan, J.J. Aaron, Critical Reviews in Environmental Science and Technology, 44 (2014) 2577-2641.

[2] A.K. Abdessalem, M.A. Oturan, N. Oturan, N. Bellakhal, M. Dachraoui, International Journal of Environmental Analytical Chemistry 90 (2010) 468-477.

[3] C.Y. Kwan, W. Chu, Water research 38 (2004) 4213-4221.

[4] M.A. Rodrigo, N. Oturan, M.A. Oturan, Chemical Reviews 114 (2014) 87208745.

[5] M. Panizza, G. Cerisola, Electrochimica Acta 51 (2005) 191-199.

[6] M. Panizza, G. Cerisola, Chemical Reviews 109 (2009) 6541-6569.

[7] I. Sirés, E. Brillas, M.A. Oturan, M.A. Rodrigo, M. Panizza, Environmental Science and Pollution Research 21 (2014) 8336-8367.

[8] A.M. Polcaro, A. Vacca, M. Mascia, S. Palmas, Electrochimica Acta 50 (2005) 1841-1847.

[9] C.A. Martinez-Huitle, S. Ferro, Chemical Society Reviews 35 (2006) 1324-1340.

[10] M.A. Rodrigo, P. Canizares, A. Sanchez-Carretero, C. Saez, Catalysis Today 151 (2010) 173-177.

[11] P. Cañizares, C. Sáez, A. Sánchez-Carretero, M.A. Rodrigo, Journal of Applied Electrochemistry 39 (2009) 2143-2149.

[12] C.A. Martinez-Huitle, L.S. Andrade, Quimica Nova 34 (2011) 850-858.

[13] M. Catanho, G.R.P. Malpass, A.J. Motheo, Applied Catalysis B: Environmental 62 (2006) 193-200.

[14] G. Li, J. Qu, X. Zhang, J. Ge, Water research 40 (2006) 213-220.

[15] C. Carvalho, A. Fernandes, A. Lopes, H. Pinheiro, I. Goncalves, Chemosphere 67 (2007) 1316-1324.

[16] X. Zhao, J. Qu, H. Liu, Z. Qiang, R. Liu, C. Hu, Applied Catalysis B: Environmental 91 (2009) 539-545.

[17] G.R. Malpass, D.W. Miwa, A.C. Miwa, S.A. Machado, A.J. Motheo, Journal of hazardous materials 167 (2009) 224-229.

[18] G.R. Malpass, D.W. Miwa, R.L. Santos, E.M. Vieira, A.J. Motheo, Environmental Chemistry Letters 10 (2011) 177-182.

[19] F. L. Souza, C. Sáez, P. Cañizares, A. Motheo, M. Rodrigo, Journal of Chemical Technology \& Biotechnology 89 (2014) 1251-1258.

[20] L. Pinhedo, R. Pelegrini, R. Bertazzoli, A.J. Motheo, Applied Catalysis B: Environmental 57 (2005) 75-81.

[21] X. Zhao, J. Qu, H. Liu, C. Wang, S. Xiao, R. Liu, P. Liu, H. Lan, C. Hu, Bioresource technology 101 (2010) 865-869.

[22] S. Trasatti, Electrochim. Acta 45 (2000) 2377-2385.

[23] R. Pelegrini, P. Peralta-Zamora, A.R. DeAndrade, J. Reyes, N. Durán, Appl. Catal., B 22 (1999) 83-90.

[24] G. Li, M. Zhu, J. Chen, Y. Li, X. Zhang, Journal of Environmental Sciences 23 (2011) 744-748.

[25] Y. Feng, D.W. Smith, J.R. Bolton, J. Environ. Eng. Sci. 6 (2007) 277-284.

[26] M.F. Bergamini, D.P. Santos, M.V.B. Zanoni, Journal of Electroanalytical Chemistry 690 (2013) 47-52.

[27] M.N. Chong, B. Jin, C.W. Chow, C. Saint, Water research 44 (2010) 2997-3027.

[28] C. Badellino, C.A. Rodrigues, R. Bertazzoli, Journal of hazardous materials 137 (2006) 856-864.

[29] M.A Oturan. Journal of Applied Electrochemistry 30 (2000) 475-482

[30] E. Brillas, B. Boye, I. Sirés, J.A. Garrido, R.M.a. Rodríguez, C. Arias, P.-L.s. Cabot, C. Comninellis, Electrochimica Acta 49 (2004) 4487-4496. 
[31] E. Brillas, J. Casado, Water research 14 (2000) 2253-2262.

[32] E. Brillas, M.A. Banos, M. Skoumal, P.L. Cabot, J.A. Garrido, R.M. Rodriguez, Chemosphere 68 (2007) 199-209.

[33] J.-M. Fontmorin, S. Huguet, F. Fourcade, F. Geneste, D. Floner, A. Amrane, Chemical Engineering Journal 195-196 (2012) 208-217.

[34] J. Gao, G. Zhao, W. Shi, D. Li, Chemosphere 75 (2009) 519-525.

[35] M. Villanueva-Rodríguez, C.M. Sánchez-Sánchez, V. Montiel, E. Brillas, J.M.

Peralta-Hernández, A. Hernández-Ramírez, Electrochimica Acta 64 (2012) 196-204.

[36] X. Quan, S. Chen, J. Su, J. Chen, G. Chen, Separation and Purification Technology 34 (2004) 73-79.

[37] I. Iordache, S. Wilson, E. Lundanes, M. Iordache, V.L. Pavel, N. Aelenei, Environmental Engineering and Management Journal 9 (2010) 519-525.

[38] A. Kesraoui-Abdessalem, N. Bellakhal, N. Oturan, M. Dachraoui, M.A. Oturan, Desalination 250 (2010) 450-455.

[39] B. Ahmed, E. Limem, A. Abdel-Wahab, B. Nasr, Industrial \& Engineering Chemistry Research 50 (2011) 6673-6680.

[40] F.L. Souza, C. Sáez, P. Cañizares, A.J. Motheo, M.A. Rodrigo, Applied Catalysis B: Environmental 144 (2014) 121-128.

[41] F.L. Souza, C. Sáez, P. Cañizares, A.J. Motheo, M.A. Rodrigo, Industrial \& Engineering Chemistry Research 52 (2013) 9674-9682.

[42] F.L. Souza, C. Saez, P. Canizares, A.d.J. Motheo, M. Andres Rodrigo, Journal of Chemical Technology and Biotechnology 89 (2014) 1251-125

[43] I.M. Kolthoff, E. M. Carr, Analytic Chemical 25 (1953) 298-301.

[44] J.-M. Fontmorin, F. Fourcade, F. Geneste, D. Floner, S. Huguet, A. Amrane, Biochemical Engineering Journal 70 (2013) 17-22. 